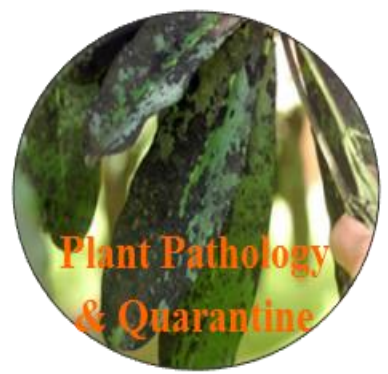

\title{
Article
}

\section{First report of Colletotrichum falcatum causing anthracnose in cardamom}

\author{
Bhuvaneswari $\mathrm{S}^{1}$, Sripriya $\mathbf{N}^{2}$, Srinithi $\mathrm{A}^{\mathbf{2}}$ and Udaya Prakash $\mathrm{NK}^{3 *}$ \\ ${ }^{1}$ Department of Plant Biology and Plant Biotechnology, Bharathi Womens College, Chennai, India \\ ${ }^{2}$ Research and Development, MARINA LABS, 14, Kavya Gardens, NT Patel Road, Nerkundram, Chennai, India \\ ${ }^{3}$ Department of Biotechnology, VELS University, Pallavaram, Chennai, India
}

Bhuvaneswari S, Sripriya N, Srinithi A, Udaya Prakash NK 2017 - First report of Colletotrichum falcatum causing anthracnose in cardamom. Plant Pathology \& Quarantine 7(2), 175-179, Doi $10.5943 / \mathrm{ppq} / 7 / 2 / 11$

\begin{abstract}
The capsules of cardamom (Elettaria cardamomum) plants cultivated in Tamil Nadu and Kerala, India were found with black spots during June to August of 2015 and 2016. Nearly 40\% crop loss was reported by farmers. The symptoms were characterized by watery, mucilaginous, yellow patches developing into sunken regions with black spots of 1-2 $\mathrm{mm}$ diam. On drying, the spots resembled the symptoms of anthracnose. These small spots coalesced to form lesions measuring 4-7 $\mathrm{mm}$ in length. The causal agent was identified as Collectotrichum falcatum. In culture, the pathogen developed as a greyish colony with sparse aerial mycelium and setae, possessing falcate, fusiform conidia with obtuse apices, and brown appressoria. Inoculating the isolated fungus onto healthy capsules resulted in recurrence of the disease symptoms after 4 days. The fungus was re-isolated and confirmed as C. falcatum. Previous reports of anthracnose in cardamom attribute the disease to $C$. gloeosporioides. This is the first report of $C$. falcatum causing anthracnose on cardamom.
\end{abstract}

Key words - anthracnose - cardamom - Colletotrichum falcatum - Elettaria cardamomum pathogenicity

\section{Introduction}

Elettaria cardamomum (L.) Maton belonging to the family Zingiberaceae, considered as the Queen of Spices, is native to India, Bhutan and Nepal. In India, the estimated production of small cardamom is 22000 tonnes, spanning an area of 69,970 hectares across Kerala, Karnataka and Tamil Nadu, as of 2016 (Spices Board India 2016). Theni of Tamil Nadu, Idukki, Udumbanchola, Peeremadu and Devikulam of Kerala state are the major areas where cardamom is grown accounting for $78 \%$ of the total production in the country.

Development of plant diseases due to environmental factors or pathogens affects the production of crops and thus economy of the farmers._Cardamom is reported to be infected with several diseases of fungal origin, of which the major fungal pathogens are Phytophthora meadii (capsule rot), Phythium vexans (rhizome rot and seedling rot), Phytophthora meadii (leaf blight), Phaeodactylium alpiniae (leaf blotch), Phakospora elettriae (leaf rust) and Colletotrichum 
gloeosporioides (brown spot) (Thomas \& Suseela 1995). Anthracnose in cardamom, caused by $C$. gloeosporioides, was reported by Suseela et al. (1988).

Examination of cardamom fields in Theni and Idukki districts in India showed the fruits of the plant were infected with_black spots during the period of June to August in 2015 and 2016. Nearly $40 \%$ crop loss was reported by the farmers. The disease symptoms are characterized as watery, mucilaginous, yellow patches developing into sunken regions with black spots of 1-2 mm. The current study reports isolation, identification and inoculation of the causal organism.

\section{Materials and methods}

\section{Isolation and identification of the pathogen}

Infected capsules of E. cardamomum, cultivated in Theni district of Tamil Nadu state and Idukki district of Kerala state in India were collected in June to July of the year 2016. The infection, resembling anthracnose was examined for the presence of causal organism. Sections of the infected capsules were placed onto potato dextrose agar (PDA) plates, under aseptic conditions and incubated at $28 \pm 2^{\circ} \mathrm{C}$. The colonies developed were identified based on the morphology of the fungi and microscopic observation.

\section{Pathogenicity test}

The pathogenicity of the isolated fungi was evaluated. The conidia of the pathogen were harvested from 5-days-old pure culture. Healthy capsules of cardamom ( 25 in number) were surface sterilized with $1 \%$ sodium hypochlorite for $2 \mathrm{~min}$ and washed thrice with sterile water. The moistened capsules were sprayed with the spores of the pathogen $\left(1 \times 10^{6} \mathrm{cfu} / \mathrm{ml}\right)$. As control, 25 capsules were immersed in sterile water. The capsules were incubated at room temperature in a moist chamber and periodically observed for the symptoms of infection. On development of symptoms, sections of the infected capsules were examined microscopically, and for confirmation of pathogenicity the fungus was re-isolated. The pathogenicity test was repeated thrice.

\section{Results}

The infection was widespread in both districts. Nearly $40 \%$ of plants were infected. Infected plants are shown (Fig 1A \& B). The infected part of the capsules showed watery, mucilaginous patches with sunken regions of black spots of size range 2-7 $\mathrm{mm}$ (Fig 1C). On PDA the isolated pathogen grew as a greyish colony with sparse aerial mycelium (Fig 2A). The microscopic nature of the fungus showed the presence of circular or clavate appressoria of size 12.5-14.5 $\times 9.5-12 \mu \mathrm{m}$. The setae were falcate, and fusiform conidia with obtuse apices, measured 15.5-26.5 $\times 4-5 \mu \mathrm{m}$ (Fig 3A-C).

Based on the cultural morphology and microscopic observation, the causal organism was identified as Colletotrichum falcatum Went. (Sutton 1980). The pathogenicity of C. falcatum was confirmed by inoculating the conidia of the pathogen onto healthy capsules of cardamom. The symptoms showed watery, mucilaginous, yellow spots on the fourth day of inoculation, followed by sunken surface and black spots in the following days (Fig 2B). The pathogenicity of C. falcatum was confirmed by re-isolating and identifying the fungus again.

\section{Discussion}

The causative agent of anthracnose in infected capsules of cardamom in India was identified as $C$. falcatum based on the morphology and microscopic observation. Evaluation of the pathogenicity of $C$. falcatum by re-infecting healthy capsules affirmed the fungus as the causative agent of anthracnose in cardamom.

Filamentous fungi of the genus Colletotrichum are considered as major plant pathogens worldwide, causing significant damage to crops and the economy. Gautam (2014) reported the pathogenesis of different species of Colletotrichum viz., C. gloeosporioides, C. capsici, C. falcatum, $C$. truncatum, $C$. sansevieriae, $C$. acutatum and $C$. coccodes on different plant species in 

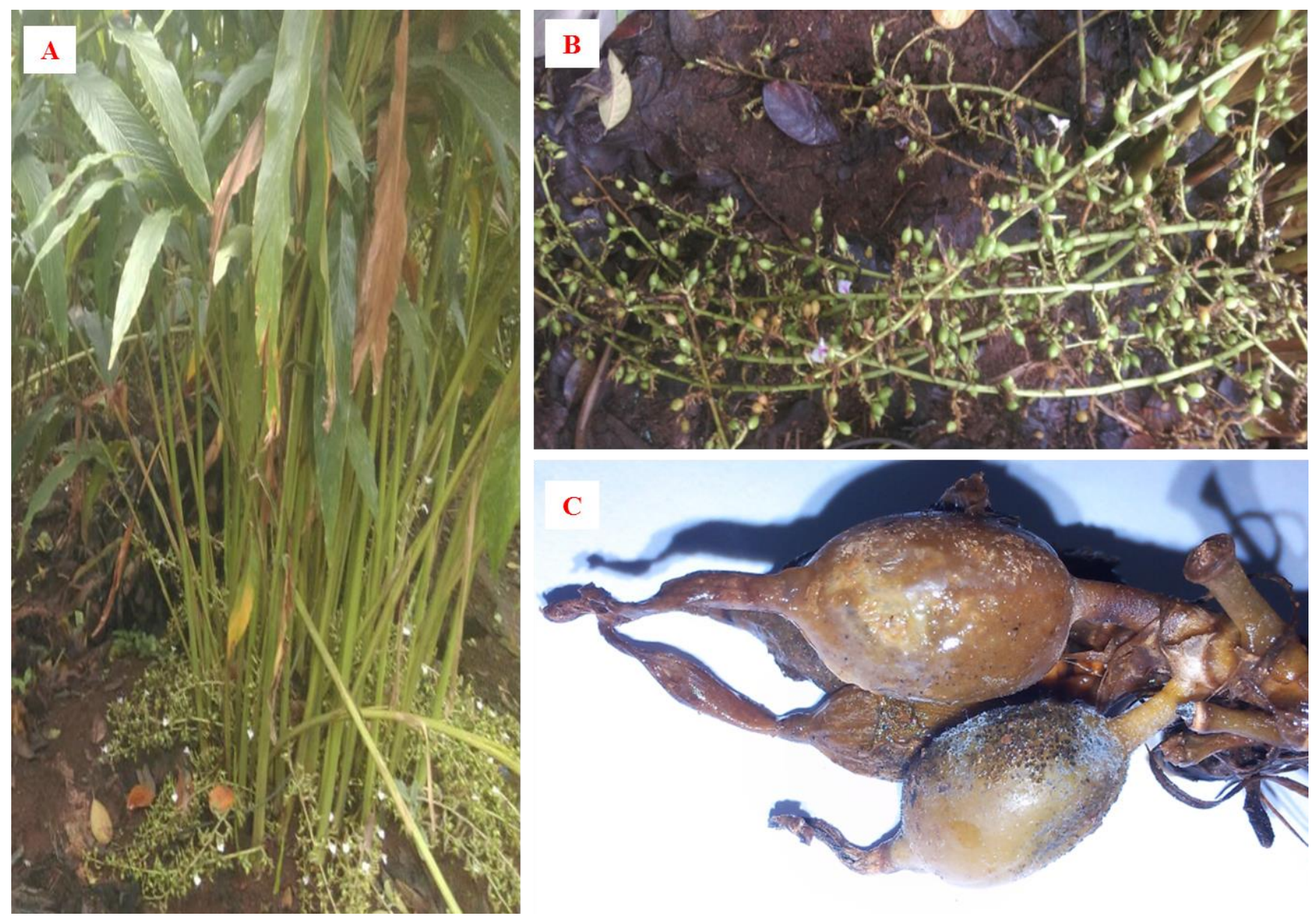

Fig 1 - A Habit of cardamom plant. B \& C Infected cardamom.
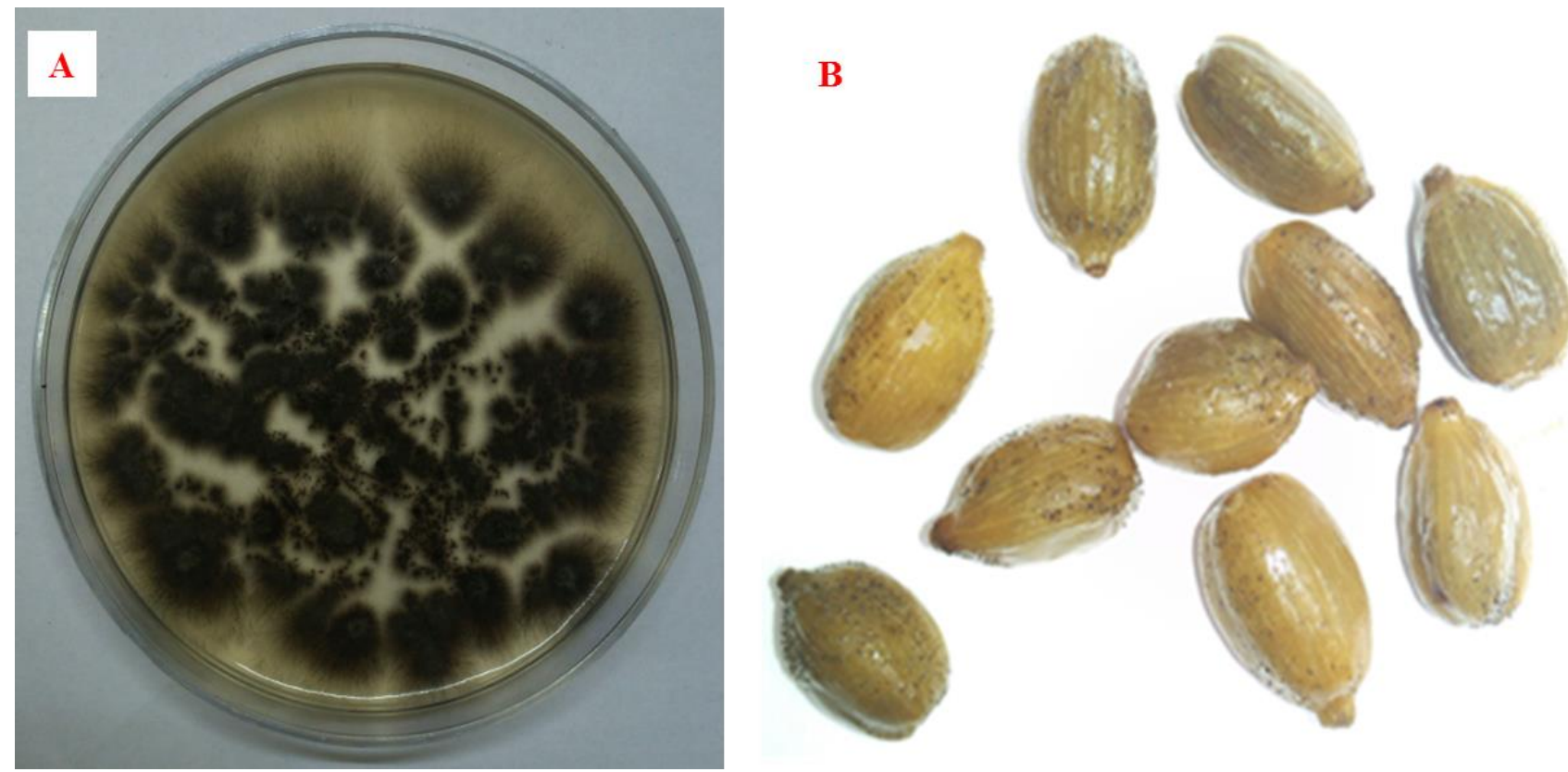

Fig 2 - A Colletotrichum falcatum on PDA. B Recurrence of symptoms on healthy capsules 

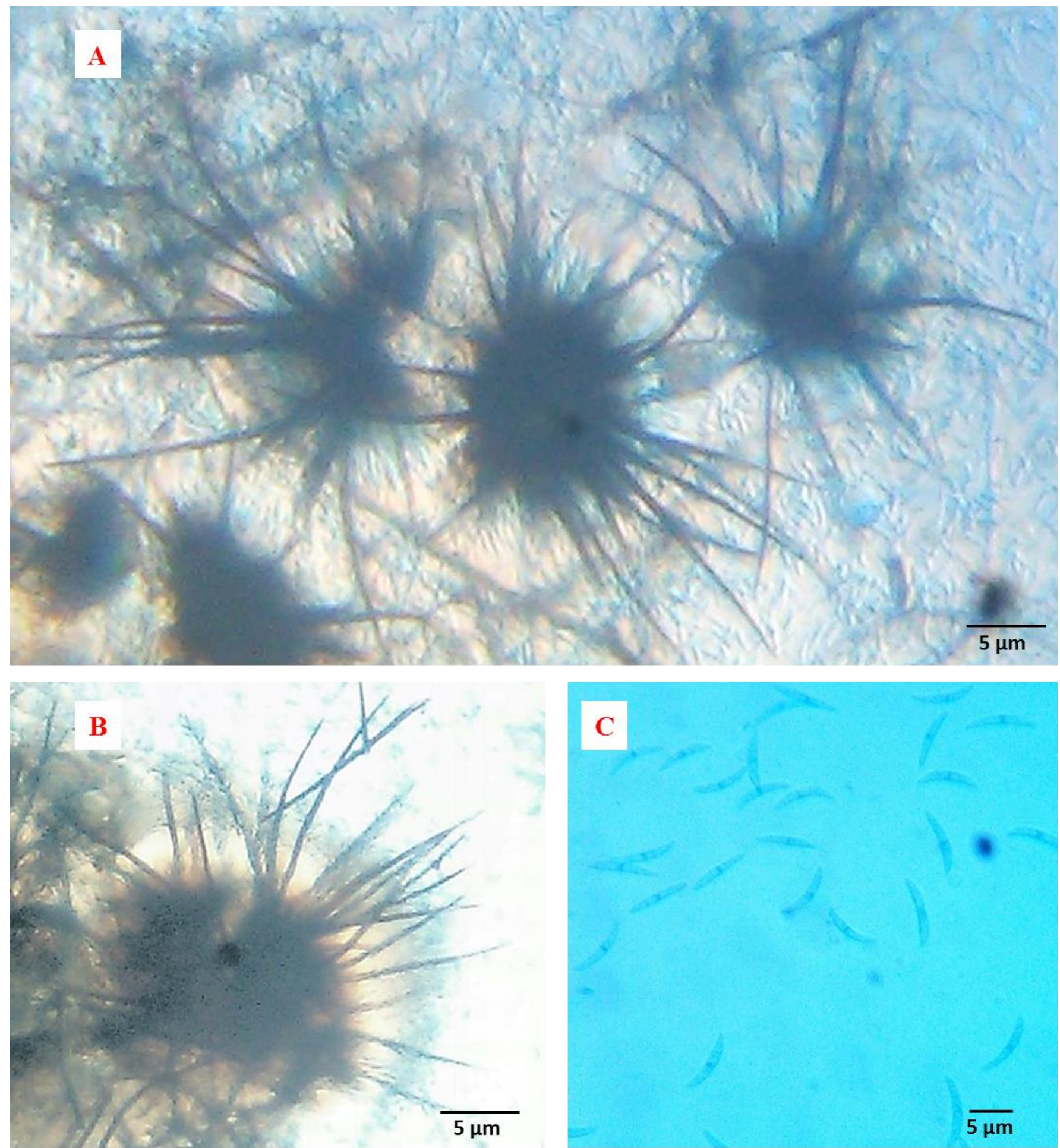

Fig 3 - Conidia. A Setae. B, C Conidiospores of C. falcatum

India. Species of Colletotrichum have the potency to infect diverse hosts as they can easily adapt to new environmental conditions (Yan et al. 2015). Though $C$. falcatum is reported to cause red rot in Saccharum officinarum (Barber 1901), there are no reports on the pathogenicity of $C$. falcatum on any other plant. It is alarming to note that the spread of $C$. falcatum on other hosts may give rise to further damage of crops. Previously, C. gloeosporioides was reported to cause anthracnose in cardamom (Suseela 1988). This is the first report of $C$. falcatum causing anthracnose on cardamom, suggesting the inclusion of $C$. falcatum as one of the pathogens on cardamom. 


\section{References}

Barber CA. 1901 - Sugarcane diseases in Godawari and Ganjam Districts. Madras Department of Land Records and Agricultural Bulletin 512, 181-194.

Gautam AK. 2014 - The genera Colletotrichum: an incitant of numerous new plant diseases in India. Journal on New Biological Reports 3(1), 9-21.

Spices Board India. 2016 - Ministry of Commerce \& Industry, Govt. of India. http://indianspices.com/sites/default/files/Major\%20spice\%20state\%20wise\%20area\%20prod uction\%202016.pdf (accessed 31 December 2016)

Suseela RB, Thomas J, Naidu R. 1988 - Anthracnose - a new disease of small cardamom. Current Science 57(24), 1346-1347.

Sutton BC. 1980 - The Coelomycetes, Commonwealth Mycological Institute, Kew, Surrey, England.

Thomas J, Suseela RB. 1995 - Fungal and bacterial diseases of cardamom (Elettaria cardamomum Maton) and their management. Journal of Spices \& Aromatic Crops 4(1), $24-31$.

Yan JY, Jayawardena MMRS, Goonasekara DI, Wang Y, Zhang W, Liu M, Huang JB, Wang ZY, Shang JJ, Peng YL, Bahkali A, Hyde KD, Li XH. 2015 - Diverse species of Colletotrichum associated with grapevine anthracnose in China. Fungal Diversity 71, 233-246. 